\title{
DISCUSSION
}

\section{The founders of Géotechnique}

\author{
J. B. BURLAND (2008). Géotechnique 58, No. 5, 327-341
}

J. Sharp, Geo-Design, Jersey, UK

\section{Dr H Q GOLDER 1911-1990}

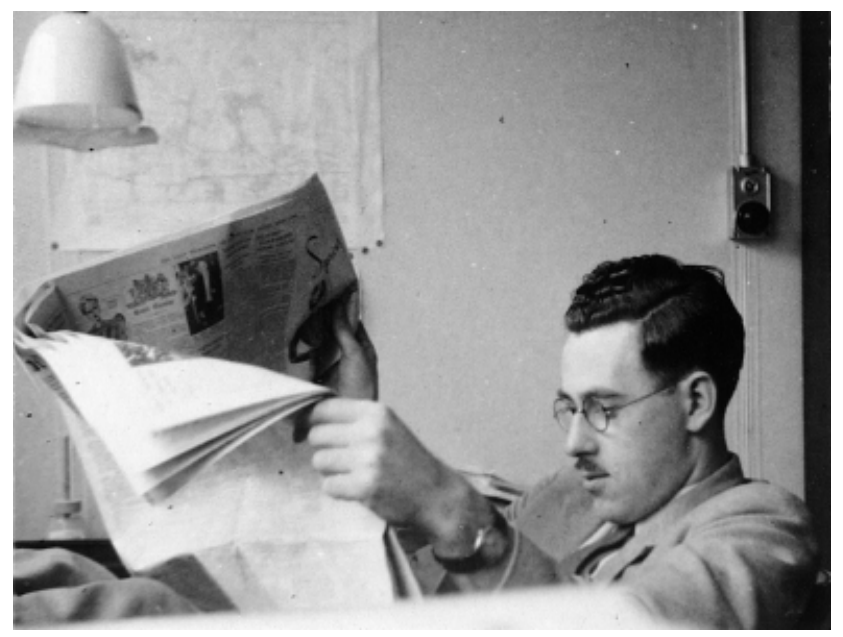

Fig. 14. Golder - a student of The Times

Professor John Burland has provided an extremely perceptive and colourful vignette of Golder, and in particular his association with Géotechnique - essential, concise reading, which was the epitome of Golder himself.

This contribution to Burland's paper, which was presented at the Diamond Jubilee Meeting on 9 July 2008, is intended as a tribute on behalf of all those who worked closely with Golder in practice after the formation of Golder Associates in the 1960s. We all benefited enormously from his wisdom, tenacity, honesty and innovation in translating the 'art' of soil mechanics into applied geotechnical 'engineering'.

It is an honour to be asked to provide this tribute, to which Vic Milligan, his great contemporary consulting colleague and founder partner, has also kindly contributed.

I was privileged to attend Imperial College during the golden years of soil mechanics, and was greatly inspired by the father of British soil mechanics, Professor Skempton, and his memorable lectures and an unforgettable range of case histories that illustrated the theory in practice. I joined Golder Associates in 1970, and spent 10 wonderful years in Canada and elsewhere around the world learning both the art and the practice of geotechnics, notably on 'difficult' and testing projects that were very much in line with Golder's spirit as an innovator and a fundamental thinker. Subsequently, when Golder retired to Jersey in the 1980s, we met not infrequently to discuss projects that often lay far beyond the textbook, and to receive his studious and erudite comments on papers that he 'kindly' reviewed for me. Scrawled across the top of the paper were the questions both posed and answered by HQG, such as 'Was it worth reading?' What a relief to get a 'Yes'!

Golder himself, until his retirement, was always at the helm of Golders, which by the 1970 s numbered more than 100 people, and was expanding rapidly. As a relatively young engineer, I found myself increasingly summoned to the Mississauga office from Vancouver to get involved in his projects, and in so doing learnt his three guiding principles of geotechnical consulting: principles, professionalism and product.

Golder was by nature both inquisitive and intellectual, and he always approached each specific technical challenge in a somewhat careful, retiring and hesitant way that underlined his diligence and prudence.

In the early year with Golders I worked on very largescale landslides in Quebec, induced by mining, and saw much of Golder's personal intervention and wisdom. After one nearly catastrophic event that involved the adjacent town, and after the appointment of Professor Arthur Cassagrande to carry out an independent assessment for the American owners, Golder became deeply interested in this formative project and the subtlety of varved clays underlying major glacial deposits. After study and inspection, Cassagrande delivered his sombre verdict on a grey, wintry day in February: he could not understand how such slopes could have failed so violently. Golder visibly sighed, and with more or less a clean bill of health we proceeded to work on

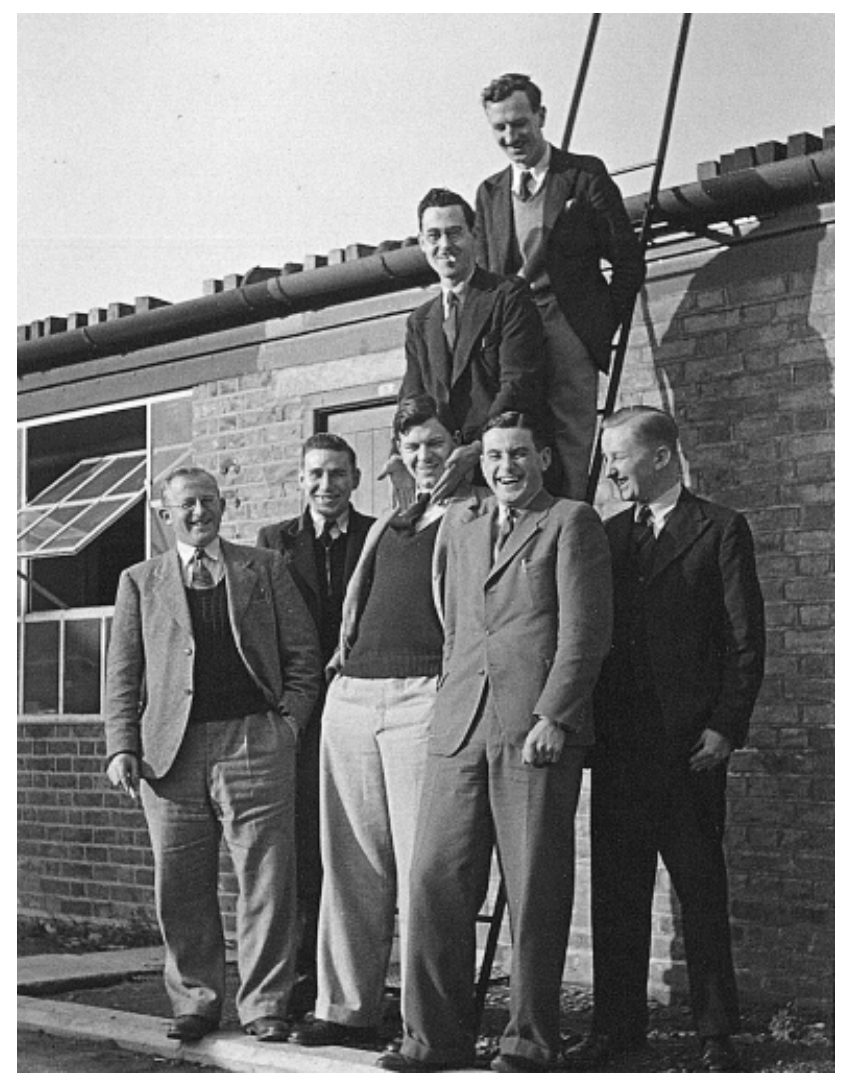

Fig. 15. BRS, the firm foundation: 1930s. H. Q. Golder (top of the ladder) seen here with his assistants Alec Skempton (front middle) and Dr Leonard Cooling (extreme left) 
the project for a further 20 years! (On the same occasion, Cassagrande, on being asked his opinion on the equally impressive rock slides, apologised about his lack of knowledge of the 'new' subject of 'rock mechanics', but rather gravely stated his intention of studying this in his reincarnation! I think he actually smiled amidst the laughter that followed.)

Golder was a great mentor, who by example and personal inspiration shaped the technical prowess of the company. He did not suffer fools, whether they be clients or colleagues. As a result of his strong principles and technical honesty, he commanded and earned great respect and loyalty, and it was a common saying in those days that 'Golders never lost a good man.' Vic Milligan, his partner, remembers Golder from the outset of HQ Golder and Associates as being extremely fair, and as a person who treated him (20 years his junior) as an equal, and brought him up to his level 'so very considerate'.

Like others, I would work on Golder's personal projects, many of which were highly innovative, including frozen, artificial islands in the Arctic, and after due research and development, the results and findings would be encapsulated in letters to clients. After years of frustration, working with Winnipeg Hydro on river closures, I was tasked with the issue of till segregation in fast flowing rivers - to 'prove' the point, as Golder put it. After stating the case yet again, and pointing out that the client had spent large sums of money in consultations and now on proof, he signed off his observations with the words: 'I look forward to your reaction, however violent. Yours, Golder.' There was no 'HQ', no 'Dr', and never 'Hugh'! Who would dare to risk future business with such blunt honesty today?

In terms of Product, he was meticulous and fastidious. He would receive - and, I am sure, read - every report that Golders issued, at least well into the 1970s. He would then, if the situation demanded, visit the author unannounced with a detailed critique written in the report, and discuss pertinent issues with him. He would often fly across Canada to do this, and in my opinion caused everyone to think very carefully before applying pen to paper. Brevity and not too many significant figures were common themes of his farreaching reviews. Apparently, early on in this process and following a meeting, a client walked away with the wrong report, covered with Golder's critique. Thereafter, all client reports were clearly differentiated by green covers; red was reserved for the potentially more 'dangerous' office copies!

One of the more interesting and unusual projects that Golder Associates had in the early 1970s involved Oak Island, just off the coast of Nova Scotia, within which lay the renowned 'Money Pit' and supposedly the pirate Bluebeard's treasure. In the 1970s an entrepreneurial but handsomely funded group called the Triton Alliance (which included John Wayne, the film star) sunk a shaft to look for the treasure. This search had been preceded by many other fruitless recovery attempts, and the ground was, to say the least, 'disturbed'.

The shaft base failed as it approached permeable deposits, linked to the surrounding sea at a depth of over $100 \mathrm{ft}$. A new shaft was ordered, and I was once more summoned to head office to analyse the groundwater time response from a significant array of piezometers in order to design a dewatering scheme. At a depth of about $60 \mathrm{ft}$ problems were encountered with the new shaft, and the work had to be stopped.

The head of the group, Alex Tobias, a wealthy financial guru from Montreal, at last began to have doubts, and flew to Toronto to discuss the project with Golder and Milligan.

While they were at lunch, Vic recalls that Tobias leaned across the table and spoke earnestly to Hugh.

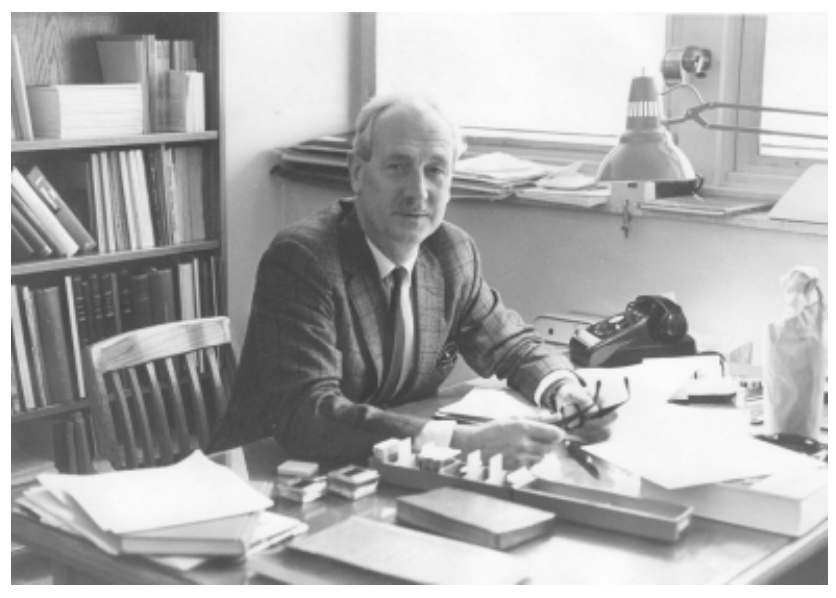

Fig. 16. Golder in command: early days in Canada

'Dr Golder - you're an older, wiser man than I am; do you honestly think there is treasure at Oak Island?'

'I certainly do!' replied Golder (in his rather tight, clipped manner of speaking, which usually inspired confidence).

'How can you be so sure?'

'It's simple; we get paid a respectable portion of it every month!'

The project was cancelled that evening.

Golder's humour was always pertinent, unashamedly honest, and to the point. At an international conference on mining slope stability he was a member of an expert panel that was posed the question 'What would you do if offered $\$ 5,000$ by a client (1970s value) to solve a mine slope stability problem?' After other eminent individuals had struggled to provide some technical 'value-for-money' strategy, Golder interjected with clear, provocative realism: 'Take the client out for a very expensive dinner and then get him to sign a requisition for $\$ 100,000$.'

Golder was a man of his time, but he left with me - and, I am sure, a great many others - the overriding importance of the engineered Product: in geotechnical terms, a successfully commissioned scheme, engineered with diligence, and designed in harmony with the natural environment. The uncertainties that accompanied innovation could not be safely addressed by emerging and increasingly complex computational methods, but must always be scrutinised and assessed on the basis of engineering experience and judgement.

The need to consider fundamental principles and to act in a professional manner were other lasting attributes that Golder left with us. All three elements remain as important today as they were to Golder.

\section{Sarah Springman and Jachen Huder, ETH Zurich}

Imbued with the spirit of celebration for, and recognition of, the achievements of Géotechique over 60 years, and in

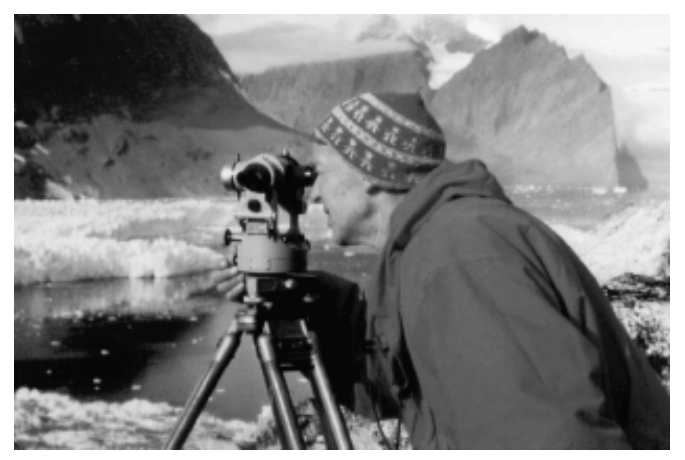

Fig. 17. Robert Haefeli (photograph, Professor Jachen Huder) 
response to stimulus from Professor John Burland CBE FRS, we were keen to add further background to two of the early Swiss co-founders (Burland, 1968), and to share some historic photographs of significant personalities taken at the time of the 3rd ICSMFE in Zurich in 1953.

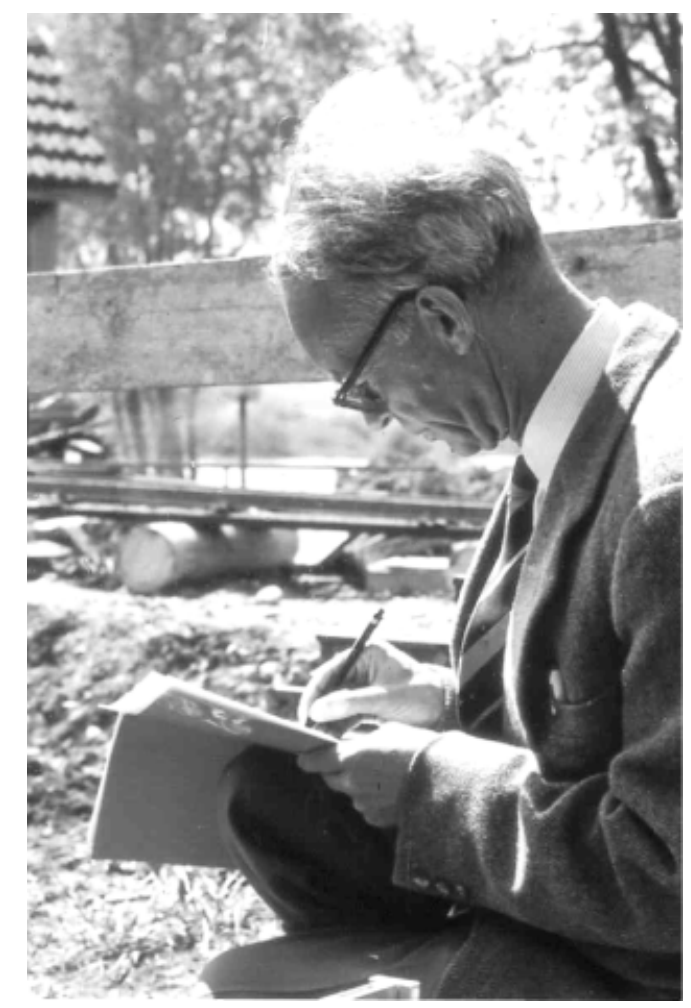

Fig. 18. Robert Haefeli in later years (photograph, Professor Jachen Huder)

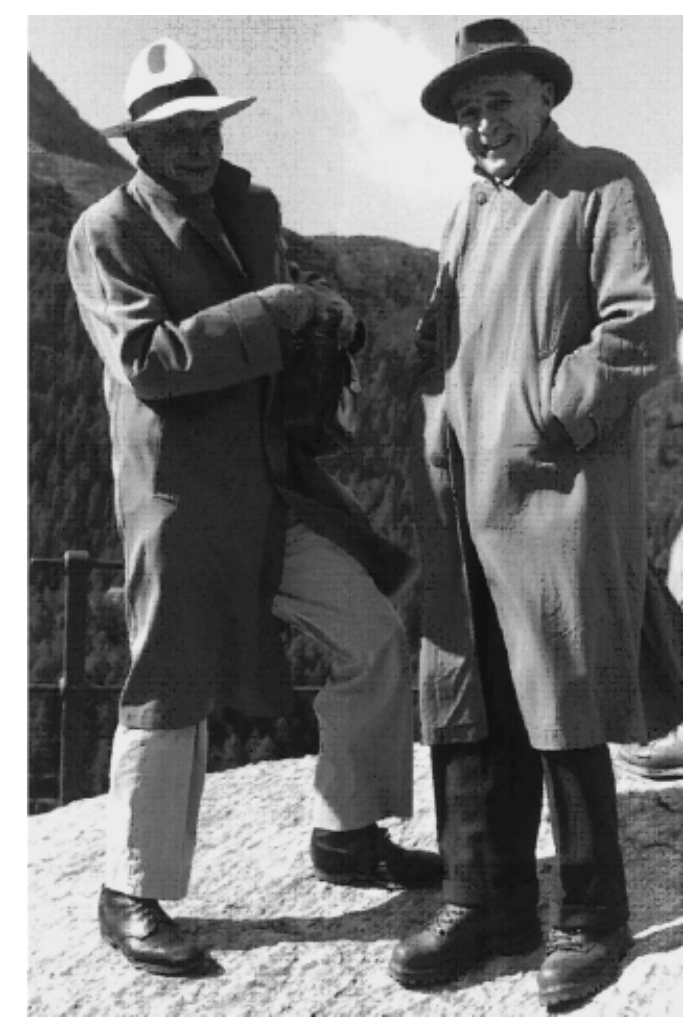

Fig. 19. Professor Karl Terzaghi (left) talking with Professor Eugen Meyer-Peter (right); Maloja Pass, 1953 (photograph, Professor Jachen Huder)
The two German-speaking Swiss founders, Professor Dr Robert Haefeli and Dr Armin von Moos, were key figures at ETH Zurich during the years in which soil mechanics was beginning to develop. They studied civil engineering and geology respectively in the 1920 s, with their doctorates following on in the mid to late 1930s. These were achieved in combination with their normal employment as assistants at ETH, when they also worked together on setting up the first soil mechanics laboratory in the institute housing the Hydraulic Structures Laboratory (Versuchsanstalt für Wasserbau, VAW) in 1935, which was then renamed the Versuchsanstalt für Wasserbau und Erdbau (VAWE).

Robert Haefeli (Figs 17 and 18) was fascinated by the alpine environment, and spent considerable time researching into the behaviour of snow and ice as well as soil, and how to analyse and model this behaviour. He was a man of great enthusiasms, and Professor Jachen Huder recalls an occasion on which Haefeli, when inspecting a glacier, warned that it

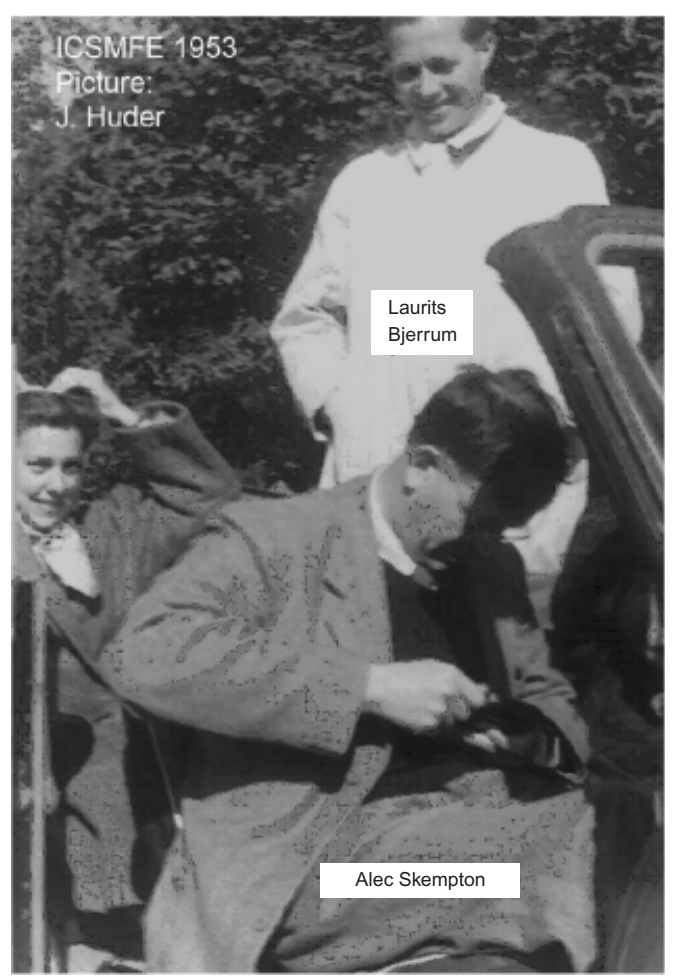

Fig. 20. Professor Alec Skempton accompanied by Mrs Nancy Skempton, designer of the front cover of Géotechnique, and former ETH Zurich doctoral researcher Dr Laurits Bjerrum; Maloja Pass, 1953 (photograph, Professor Jachen Huder)

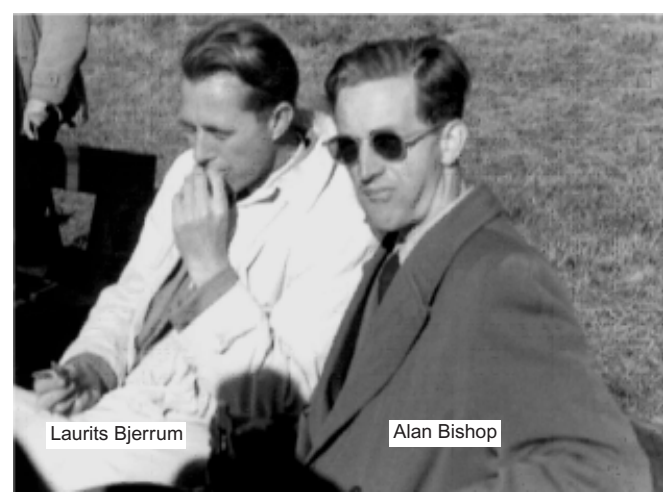

Fig. 21. Dr Laurits Bjerrum and Dr Alan Bishop, Maloja Pass, 1953 (photograph, Professor Jachen Huder) 
was safe only to cross it one at a time. Having reached the middle of the glacier, he was suddenly struck by some crystal feature and called everyone over to share his discovery! History does not relate what happened, other than that all returned safely from their escapade.

At the time of the 3rd ICSMFE in Zurich in 1953 Jachen
Huder took a series of fascinating photographs during an excursion to the most south-eastern part of Graubunden, the Maloja Pass in the Engadine, where it is possible to descend into Italy. They show several famous international geotechnical researchers and their host, Professor Eugen MeyerPeter, director of the VAWE, ETH Zurich (see Figs 19 to 21). 